\title{
Investment Risk Analysis On Bitcoin With Applied of VaR- APARCH Model
}

\author{
Irwan Kasse ${ }^{1}$, Andi Mariani' ${ }^{2}$, Serly Utari' ${ }^{3}$, Didiharyono D. ${ }^{4}$ \\ 1,2,3 Mathematics Departement, Alauddin State Islamic University Makassar, Indonesia \\ ${ }^{4}$ Andi Djemma University, Palopo, Indonesia \\ 1irwan.msi@uin-alauddin.ac.id; ${ }^{2}$ andi.mariani@uin-alauddin.ac.id; 3 60600116030@uin-alauddin.ac.id; \\ 4muh.didih@gmail.com
}

\begin{tabular}{l}
\hline \\
\hline Article History: \\
Received : 14-10-2020 \\
Revised : 25-11-2020 \\
Accepted : 08-12-2020 \\
Online : 15-04-2021 \\
\hline
\end{tabular}

Keyword:

Investment risk;

Time series;

Heteroscedasticity;

VaR-APARCH.

\begin{abstract}
Investment can be defined as an activity to postpone consumption at the present time with the aim to obtain maximum profits in the future. However, the greater the benefits, the greater the risk. For that we need a way to predict how much the risk will be borne. Modelling data that experiences heteroscedasticity and asymmetricity can use the Asymmetric Power Autoregressive Conditional Heteroscedasticity (APARCH) model. This research discusses the time series data risk analysis using the Value at Risk-Asymmetric Power Autoregressive Conditional Heteroscedasticity (VaR-APARCH) model using the daily closing price data of Bitcoin USD period January 12019 to 31 December 2019. The best APARCH model was chosen based on the value of Akaike's Information Criterion (AIC). From the analysis results obtained the best model, namely ARIMA $(6,1,1)$ and APARCH $(1,1)$ with the risk of loss in the initial investment of IDR $100,000,000$ in the next day IDR $26,617,000$. The results of this study can be used as additional information and apply knowledge about the risk of investing in Bitcoin with the VaR-APARCH model.

\section{A. INTRODUCTION}

The capital market is a means for the public and investors to choose various forms of investment with the aim of obtaining the maximum benefits in the future. One form of investment that is popular today is the creation of virtual money in cyberspace, known as cryptocurrency (Raymaekers, 2015). The formation of bitcoin as a virtual currency resulting from cryptography, is very likely to continue to grow in the future. In line with the concept of cryptocurrency, this is identical to the requirements for a legal medium of exchange, which is unique, not easily damaged and mutually agreed upon (Guesmi, et al., 2019). With the various cryptocurrencies, bitcoin is one of the most widely used investments because it has several advantages, including blockchain technology (Sovbetov, 2018).

Blockchain is computer software that contains a data base and functions as a world accounting ledger with a computer system that is distributed to the entire computer network of Bitcoin users in a peer-to-peer manner following an agreed protocol (Chu, 2018). Peer-topeer is connecting from one computer to another in a large network of all Bitcoin users. After 
the transaction data is recorded and sent, the data cannot be changed because data changes must be made by all series of blocks. This is very difficult because changing it requires the agreement of all network users. Blockchain records a chronological history of all transactions that have occurred in a series of blocks connected to one another. Thus, transactions with virtual bitcoin money are essentially secret signature links (Sovbetov, 2018).

Even though bitcoin investing has many advantages, it does not mean investing in bitcoin has no risk, of course, any investment that provides benefits will certainly face risks. Therefore, we need a way to find out how much risk will be borne in investing. Thus, the Value at Risk-Asymmetric Power Autoregressive Conditional Heteroscedasticity (VaR-APARCH) model is one of the models used to analyze investment risk (Hidayatullah \& Qudratullah, 2017)(Gunay \& Khaki, 2018).

Value at Risk (VaR) is a measure that states the largest loss that an investor may experience in a certain period or period which is estimated with a certain predetermined level of confidence (Giot \& Laurent, 2013). One of the most widely used models in modeling time series data is the Box-Jenkins method or ARIMA model. The ARIMA model can also be used to estimate currency exchange rates in bitcoin transactions, including forecasting cryptocurrency exchange rates in a high volatility environment (Bakar \& Rosbi, 2017). In general, bitcoin data has an error variance that varies from time to time or is called heteroscedasticity. To model data that has heteroscedasticity, APARCH model introduced by Granger, Ding, and Eagle can be used in 1993 (Ilupeju, 2016). An important point in the APARCH model is to change the second order of the error value in a flexible form and has an asymmetric coefficient on the difference between the effects of good news and bad news (Gunay \& Khaki, 2018) (Irene, Wijaya, \& Muhayani, 2020).

There are many studies that use the APARCH model to overcome asymmetric and heteroscedasticity conditions. Among them, research that explains the EGARCH, TGARCH and APARCH models are suitable for data experiencing heteroscedasticity conditions (Thorlie, Song, Wang, \& Amin, 2014). Furthermore, it is also obtained that the APARCH model is statistically effective in estimating VaR from the Shangsai Composite Index compared to the GARCH model (Xuehue \& Huiyao, 2012), the APARCH model combined with the heavy-tail distribution model provides a good alternative for modelling stock returns (Ilupeju, 2016), the APARCH model outperforms the GARCH model in estimating future energy volatility (Gunay \& Khaki, 2018), and obtained the results of their research using the APARCH, EGARCH and TGARCH methods to predict the world gold price (Irene et al., 2020).

Other research also shows that the best model results to calculate the risk of Var-APARCH $(1,1)$ (Hidayatullah \& Qudratullah, 2017). And found that the APARCH $(1,1)$ model with the student-t distribution are able to model volatility at five foreign exchange selling rates against the rupiah (Nugroho \& Susanto, 2017), including also capable to model the stock market volatility (Conrad, Karanasos, \& Zeng, 2011), and able to calculate risk in the commodity market using risk measurement tools (VaR), namely the ARCH and APARCH models (Giot \& Laurent, 2013).

There is also research that has found that the APARCH (2.1) model to calculate the rupiah exchange rate against the dollar (Elvitra, Warsito, \& Hoyyi, 2013). Which is certain that the AA model can be used in various cases analyzed. As research shows that the EGARCH, GJT-GARCH, 
TGARCH, VGARCH, NGARCH, IGARCH and APARCH models are able to model pathogens in marine recreation sites (Ali, 2013). The APARCH model with the skewed student's $t$ distribution are the most effective in modelling and predicting the daily stock index (Thorlie, Song, Amin, \& Wang, 2015), and also obtained the results of research which explains that the APARCH model with standardized distribution of type IV accurately in modeling the risk of VaR (Stavroyiannis, 2016). Based on this explanation, it can be ascertained that the VARAPARCH model can be used to analyze the risk of investing in Bitcoin. With the aim of the study, namely to determine the amount of investment risk in Bitcoin obtained from VaR analysis with the Asymmetric Power Autoregressive Conditional Heterocedasticity (VaRAPARCH) model.

\section{B. METHODS}

The data used in the study is secondary data obtained from https://www.yahoo.finance.com with the daily closing price of Bitcoin in the period 1 January 2019 untill 31 December 2019 totaling 365 data. The analysis steps carried out in this study are as follows;

\section{Calculate bitcoin returns.}

Return is the result of the rate of return obtained as a result of the investment made. There are two types of returns that are used to calculate risk, namely simple net return $\left(r_{t}\right)$ and log return $\left(R_{t}\right)$ (Hidayatullah \& Qudratullah, 2017).

$$
r_{t}=\frac{P_{t}-P_{t-1}}{P_{t-1}}=\frac{P_{t}}{P_{t-1}}
$$

and

$$
R_{t}=\ln \left(\frac{P_{t}}{P_{t-1}}\right)=\ln \left(P_{t}\right)-\ln \left(P_{t-1}\right)
$$

Where, $t=$ current time; $r_{t}=$ simple net return in period $t ; R_{t}=\log$ return in period $t ; P_{t}=$ asset value in period $t$; and $P_{t-1}=$ asset value in period $t-1$. And then calculating descriptive statistics of returns in the form of mean, standard deviation, skewness, kurtosis.

\section{Stationarity test on bitcoin return data.}

The stationary test is the first stage taken in testing the form of time series data. If it is found that the data is not stationary, it will be differentiated or differentiated in the data so that the data becomes stationary. One of the stationaryity tests used is the Augmented Dickey Fuller (ADF) test with the following equation.

$$
\begin{aligned}
& Z_{t}-Z_{t-1}=\rho Z_{t-1}-Z_{t-1}+e_{t} \\
& \Delta Z_{t}{ }^{\prime}=(1-\rho) Z_{t-1}+e_{t} \\
& \Delta Z_{t}{ }^{\prime}=\delta Z_{t-1}+e_{t}
\end{aligned}
$$

Where, $Z_{t}=$ actual data for period $t ; Z_{t-1}=$ actual data for period $t-1 ; \rho=$ autoregression value; $\Delta Z_{t}{ }^{\prime}=$ the results of the difference data in period $t ; \delta=$ regression coefficient; and $e_{t}=$ residual value.

With hypothesis:

$$
\begin{aligned}
& H_{0}: \alpha_{1}=\alpha_{2} \ldots \alpha_{p}=0 \text { (Not stationarity) } \\
& H_{1}: \exists \alpha_{1} \neq 0, i=1,2 \ldots, p \text { (Stationarity) }
\end{aligned}
$$

And significance level $\alpha=5 \%$ 


\section{Identifying the Box Jenkins model by looking at the Autocorrelation Function (ACF)} and Partial Autocorrelation Function (PACF) plots.

In time series data modeling, the Box-Jenkins model is usually used. The stationary time series models are the AR, MA, and ARMA models. Meanwhile, the non-stationary time series model is the ARIMA model, with the following models (Syarif, 2020)(Didiharyono \& Syukri, 2020):

Autoregressive (AR) Model

$$
Z_{t}=\phi_{1} Z_{t-1}+\phi_{2} Z_{t-2}+\cdots+\phi_{p} Z_{t-p}+a_{t}
$$

Moving Average (MA) Model

$$
Z_{t}=a_{t}-\theta_{1} a_{t-1}-\theta_{1} a_{t-2}-\cdots-\theta_{q} a_{t-q}
$$

Autoregressive Moving Average (ARMA) Model

$$
Z_{t}=\phi_{1} Z_{t-1}+\cdots+\phi_{p} Z_{t-p}+a_{t}-\theta_{1} a_{t-1}-\cdots-\theta_{q} a_{t-q}
$$

Autoregressive Integrated Moving Average (ARIMA) Model

$$
\phi_{p}(B)(1-B)^{d} Z_{t}=\theta_{q}(B) a_{t}
$$

Where, $Z_{t}=$ dependent variable; $Z_{t-1}, Z_{t-2}, \ldots, Z_{t-p}=$ independent variable; $\phi_{1}, \phi_{2}, \ldots, \phi_{p}=$ auto regressive coefficient; $a_{t}=$ model parameter error; $\theta_{1}, \theta_{2}, \ldots, \theta_{p}=$ moving average coefficient; $a_{t-s}, a_{t-2 s}=$ Previous error value; and $B=$ blackshift operator. Next, estimate the parameters using the maximum likelihood.

\section{Test the ARCH effect by using the Lagrange Multiplier test.}

The ARCH Lagrange-Multiplier (LM) test is used to check cases of heteroscedasticity or the ARCH/ GARCH effect on the residuals of the ARIMA model that has been formed beforehand by regressing the squares of the model residuals (Tsay, 2014).

$$
a_{t}^{2}=\alpha_{0}+\alpha_{1} a_{t-1}^{2}+\alpha_{2} a_{t-2}^{2}+\cdots+\alpha_{m} a_{t-m}^{2}+e_{t}
$$

With hypothesis:

$H_{0}=\alpha_{1}=\alpha_{2}=\cdots=\alpha_{m}=0$ (There is no ARCH/GARCH effect in the residual until lag-m). $H_{1}=$ There is at least one value $\alpha_{i} \neq 0, i=1,2, \ldots, \mathrm{m}$ (there is an ARCH / GARCH effect in the residual until lag- $m$ ).

\section{Estimasi parameter GARCH and APARCH.}

The general form of the APARCH $(p, q)$ model is:

$$
\sigma_{t}^{2}=\omega+\sum_{i=1}^{p} \alpha_{i}\left(\left|\varepsilon_{t-1}\right|-\gamma_{i} \varepsilon_{t-i}\right)^{\delta}+\sum_{j=1}^{q} \beta_{j} \sigma_{t-j}^{\delta}
$$

with

$$
\omega=0, \alpha_{i}>0, \beta_{j}>0, \delta>0 \text { and }-1<\gamma_{i}<1
$$

Where $\omega, \alpha_{i}, \mu, \beta_{j}$ and $\gamma_{i}$ are the estimated parameters, $\delta$ is estimated using the Cox Box transformation under standard deviation conditions, $\gamma_{i}$ is leverage effect (Epaphra, 2016) (Katsiampa, 2017).

\section{Calculate the VaR value.}

Value at risk is a risk measurement tool that can be used to assess the worst possible loss that an investor may experience, either individually or in the form of a portfolio in a certain period and a certain level of confidence that has been set. Mathematically, VaR can be formulated as follows (Stavroyiannis, 2016). 


$$
V a R=\mu+\sigma \Phi^{-1} \sqrt{t}
$$

Where, $\mu=$ share average; $\sigma=$ Estimated value of volatility; $\Phi^{-1}=Z$-score; $\alpha=$ Significance level; and $t=$ holding period.

\section{RESULT AND DISCUSSION}

\section{Bitcoin Price}

This research uses data on the price of bitcoin USD in the period 1 January $2019\left(t_{0}\right)$ until 31 December $2019\left(t_{365}\right)$ as much as 365 data obtained from https://www.yahoo.finance.com can be seen in Table 1. The bitcoin price data is calculated based on the return value using the log return value as Equation (1).

Table 1. Calculation Results of Bitcoin Price Returns

\begin{tabular}{ccc}
\hline Period (t) & $\begin{array}{c}\text { Bitcoin Price } \\
\text { (USD) }\end{array}$ & Return \\
\hline 0 & 3843.52002 & 0 \\
\hline 1 & 3943.409424 & 0.025989 \\
\hline 2 & 3836.741211 & -0.02705 \\
\hline 3 & 4076.632568 & 0.06019 \\
\hline$\vdots$ & $\vdots$ & $\vdots$ \\
\hline 365 & 7193.599121 & -0.01363 \\
\hline
\end{tabular}

The return value of bitcoin is obtained using Equation (1) so that,

For $t=1$, then $R_{1}=\left(\frac{3943.409424-3843.52002}{3843.52002}\right)=0.025989$

For $t=2$, then $R_{2}=\left(\frac{3836.741211-3943.409424}{3943.409424}\right)=-0.02705$

For $t=3$, then $R_{3}=\left(\frac{4076.632568-3836.741211}{3836.741211}\right)=-0.06019$

Until, for $t=365$, then $R_{364}=\left(\frac{7193.599121-7292.995117}{7292.995117}\right)=-0.01363$.

The results of descriptive analysis of bitcoin data can be seen in Table 2 .

Table 2. Descriptive Statistics Value of Bitcoin Return

\begin{tabular}{cc}
\hline Descriptive Statistics & Value \\
\hline Average & 0.002344 \\
\hline Maximum & 0.173560 \\
\hline Minimum & -0.140857 \\
\hline Standard deviation & 0.03560068 \\
\hline Skewness & 0.5661341 \\
\hline Kurtosis & 7.641383
\end{tabular}

Based on the return value of bitcoin that has been obtained in Table 2, descriptive statistical value is obtained with average return of 0.002344 . Then the skewness value is obtained a value of 0.5661341 which indicates that bitcoin return data is leaning to the right or more data is on the right. Furthermore, for the value of kurtosis, a value of 7.641383 is obtained, which means that the data has a fairly high price volatility, because the value is above the value of 3 , causing heteroscedasticity in the data. 


\section{Stationary Test}

Based on the return data on bitcoin prices, a time series plot is obtained as shown in Figure 1 as follows:

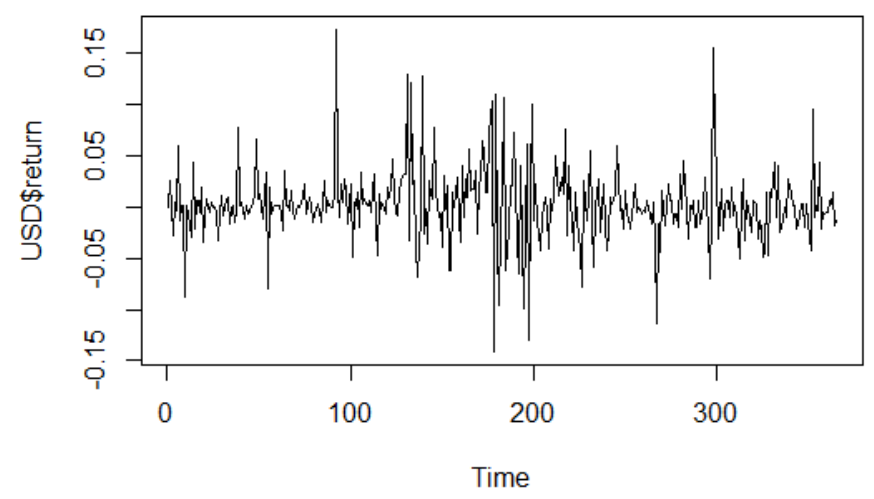

Figure 1. Plot of Bitcoin Return Data

Based on the return data plot in Figure 1, it can be seen that the data is experiencing an unstable condition, so the data is not stationary. Next, the first--order differencing on these data. The plot of the results of the first-order differencing is Figure 2 as follows.

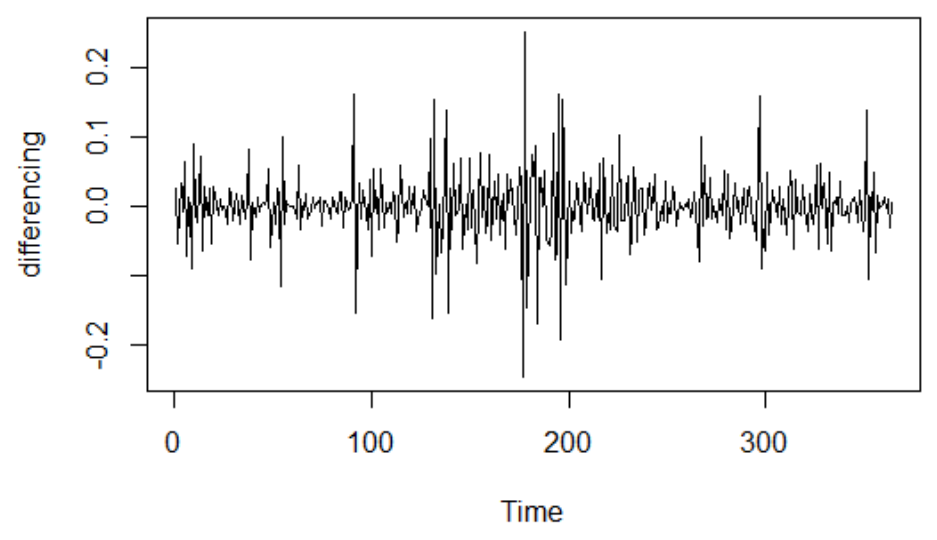

Figure 2. Plot of the first-order differencing

Because the plot of first-order differencing is stationary as Figure 2, to be surer the Augmented Dickey Fuller (ADF) test will be carried out as shown in Table 3.

Table 3. Augmented Dickey Fuller (ADF) test

\begin{tabular}{cc}
\hline \multicolumn{2}{c}{ Augmented Dickey Fuller (ADF) } \\
\hline T-Statistics & -10.214 \\
\hline P-Value & 0.01 \\
\hline
\end{tabular}

From Table 3, the p-value is 0.01 . This value is smaller than the significance level of $5 \%$ and the $0.01<0.05$, then $\mathrm{H}_{0}$ is rejected or $\mathrm{H}_{1}$ is accepted, meaning that the data from the first order differencing results are stationary.

\section{Identify the Box-Jenkins Model}

Identification of the Box-Jenkins model is done by looking at the plots of the ACF and PACF to find out the AR and MA models from the time series data. Based on the return on bitcoin prices, the ACF and PACF results are obtained as follows. 


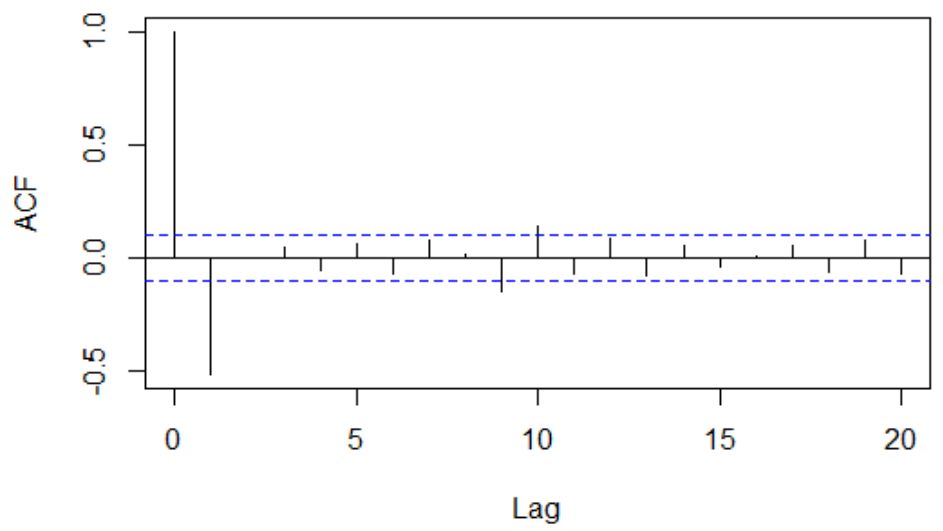

Figure 3. ACF Plot Data

And the autocorrelation function value is shown in the Table 4.

Table 4. Autocorrelation Function Value

\begin{tabular}{cccccc}
\hline Lag & ACF & Lag & ACF & Lag & ACF \\
\hline 0 & 1.000 & 7 & 0.076 & 14 & 0.051 \\
1 & -0.516 & 8 & 0.017 & 15 & -0.044 \\
2 & -0.001 & 9 & -0.148 & 16 & 0.010 \\
3 & 0.045 & 10 & 0.137 & 17 & 0.052 \\
4 & -0.057 & 11 & -0.074 & 18 & -0.064 \\
5 & 0.060 & 12 & 0.087 & 19 & 0.080 \\
6 & -0.073 & 13 & -0.082 & 20 & -0.069 \\
\hline
\end{tabular}

Based on Figure 3 and Table 4, it can be seen that the lag is cut off at lag-1 and decreases exponentially, so that the model that can be generated is MA (1). Meanwhile, the PACF plot data can be seen in Figure 5 below.

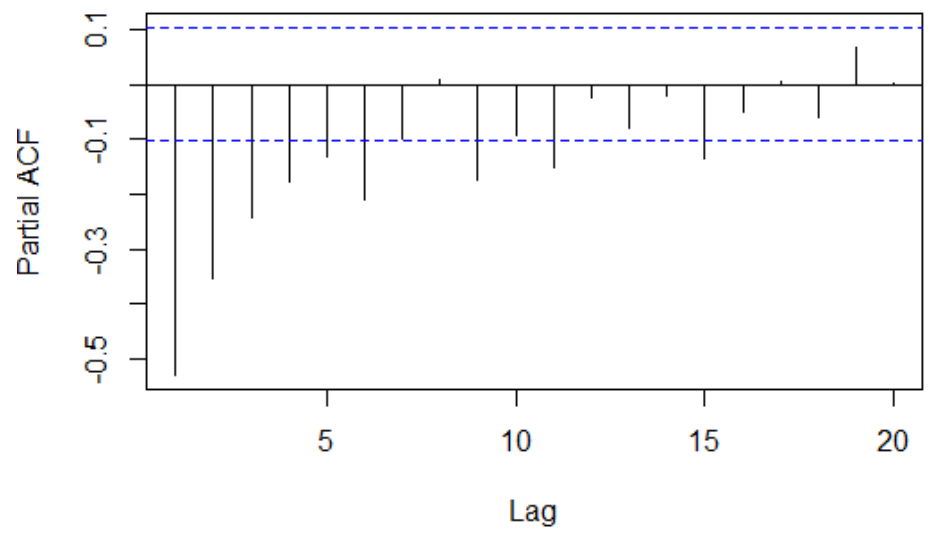

Figure 4. PACF Plot Data

And the Partial Autocorrelation Function value is shown in the Table 5.

Table 5. Partial Autocorrelation Function Value

\begin{tabular}{cccccccc}
\hline Lag & PACF & Lag & PACF & Lag & PACF & Lag & PACF \\
\hline 1 & -0.516 & 6 & -0.193 & 11 & -0.150 & 16 & -0.083 \\
2 & -0.363 & 7 & -0.103 & 12 & -0.026 & 17 & -0.013 \\
3 & -0.225 & 8 & -0.001 & 13 & -0.094 & 18 & -0.067 \\
4 & -0.228 & 9 & -0.179 & 14 & -0.027 & 19 & 0.050 \\
5 & -0.134 & 10 & -0.100 & 15 & -0.105 & 20 & 0.007 \\
\hline
\end{tabular}


Based on Figure 4 and Table 5, it can be seen that the lag is truncated after lag 6 then decreases exponentially, so that the predictive model that can be generated is AR (6). The provisional model estimates for ARIMA (p,d,q) are ARIMA $(1,1,0)$, ARIMA $(1,1,1)$, ARIMA $(2,1,0)$, ARIMA $(2,1,1)$, ARIMA $(3,1,0)$, ARIMA $(3,1,1)$, ARIMA $(4,1,0)$, ARIMA $(4,1,1)$, ARIMA $(5,1,0)$, ARIMA $(5,1,1)$, ARIMA $(6,1,0)$, ARIMA $(6,1,1)$.

Table 6. Estimation of the Best ARIMA Model

\begin{tabular}{|c|c|c|c|}
\hline Model & Parameter & Estimation & AIC \\
\hline $\operatorname{ARIMA}(1,1,0)$ & AR1 & -0.6691 & -936.59 \\
\hline \multirow{2}{*}{$\operatorname{ARIMA}(1,1,1)$} & AR1 & -0.5137 & \multirow{2}{*}{-1226.55} \\
\hline & MA1 & -1.0000 & \\
\hline \multirow{2}{*}{$\operatorname{ARIMA}(2,1,0)$} & AR1 & -1.0249 & \multirow{2}{*}{-1055.26} \\
\hline & AR2 & -0.5311 & \\
\hline \multirow{3}{*}{$\operatorname{ARIMA}(2,1,1)$} & AR1 & -0.6998 & \multirow{3}{*}{-1275.07} \\
\hline & AR2 & -0.3604 & \\
\hline & MA1 & -1.0000 & \\
\hline \multirow{3}{*}{$\operatorname{ARIMA}(3,1,0)$} & AR1 & -1.2262 & \multirow{3}{*}{-1109} \\
\hline & AR2 & -0.9180 & \\
\hline & AR3 & -0.3763 & \\
\hline \multirow{4}{*}{$\operatorname{ARIMA}(3,1,1)$} & AR1 & -0.7808 & \multirow{4}{*}{-1291.31} \\
\hline & AR2 & -0.5164 & \\
\hline & AR3 & -0.2212 & \\
\hline & MA1 & -1.0000 & \\
\hline \multirow{4}{*}{$\operatorname{ARIMA}(4,1,0)$} & AR1 & -1.3643 & \multirow{4}{*}{-1158.47} \\
\hline & AR2 & -1.2549 & \\
\hline & AR3 & -0.8234 & \\
\hline & AR4 & -0.3631 & \\
\hline \multirow{5}{*}{$\operatorname{ARIMA}(4,1,1)$} & AR1 & -0.8320 & \multirow{5}{*}{-1308.15} \\
\hline & AR2 & -0.6347 & \\
\hline & AR3 & -0.3979 & \\
\hline & AR4 & -0.2244 & \\
\hline & MA1 & -1.0000 & \\
\hline \multirow{5}{*}{$\operatorname{ARIMA}(5,1,0)$} & AR1 & -1.4528 & \multirow{5}{*}{-1178.18} \\
\hline & AR2 & -1.4542 & \\
\hline & AR3 & -1.1271 & \\
\hline & AR4 & -0.6921 & \\
\hline & AR5 & -0.2408 & \\
\hline \multirow{6}{*}{$\operatorname{ARIMA}(5,1,1)$} & AR1 & -0.8625 & \multirow{6}{*}{-1312.45} \\
\hline & AR2 & -0.6880 & \\
\hline & AR3 & -0.4828 & \\
\hline & AR4 & -0.3344 & \\
\hline & AR5 & -0.1312 & \\
\hline & MA1 & -1.000 & \\
\hline \multirow{3}{*}{$\operatorname{ARIMA}(6,1,0)$} & AR1 & -1.5217 & \multirow{3}{*}{-1206.39} \\
\hline & AR2 & -1.6517 & \\
\hline & AR3 & -1.4470 & \\
\hline
\end{tabular}




\begin{tabular}{|c|c|c|c|}
\hline & AR4 & -1.1046 & \\
\hline & AR5 & -0.6512 & \\
\hline & AR6 & -0.2819 & \\
\hline & AR1 & -0.8886 & \\
\hline & AR2 & -0.7539 & \\
\hline & AR3 & -0.5762 & \\
\hline $\operatorname{ARIMA}(6,1,1)$ & AR4 & -0.4672 & -1323.79 \\
\hline & AR5 & -0.2958 & \\
\hline & AR6 & -0.1897 & \\
\hline & MA1 & -1.000 & \\
\hline
\end{tabular}

From Table 6, it is obtained that the best ARIMA model is ARIMA $(6,1,1)$ with the smallest Akaike's Information Criterion (AIC) value of -1323.79 so that the model can be used for analysis at a later stage.

\section{ARCH Test}

ARCH test is used to see the heteroscedasticity effect on the best ARIMA (p,d,q) model. As for the ARCH-LM test, the following results were obtained.

Table 7. ARCH Test Results

\begin{tabular}{cc}
\hline \multicolumn{2}{c}{ ARCH test } \\
\hline Chi-Squared & 23.621 \\
\hline$P$-Value & 0.02289 \\
\hline
\end{tabular}

Based on Table 7, it is obtained P-value of 0.02289 where the $p$-value $<\alpha$. Then the decision is rejected $\mathrm{H}_{0}$ or there is an ARCH effect at ARIMA $(6,1,1)$ model.

\section{Parameter estimation GARCH and APARCH}

To overcome the effect of ARCH or heteroscedasticity data, a suitable model is needed, namely modeling with GARCH. Estimating parameters of the GARCH model can be done using the Maximum Log Likelihood method in the best ARIMA (p,d,q) model, namely ARIMA $(6,1,1)$. Identification of the GARCH (p, q) model using the p and q orders of 6 and 1 , including GARCH $(1,1)$, GARCH $(2,1)$, GARCH $(3,1)$, GARCH $(4,1)$, GARCH $(5,1)$ and GARCH $(6,1)$. Parameter estimation GARCH $(p, q)$ can be seen in the following table 5.

Table 8. Parameter estimation GARCH

\begin{tabular}{|c|c|c|c|}
\hline Model & Parameter & estimation & AIC \\
\hline \multirow{4}{*}{ GARCH(1,1) } & $\mu$ & $3.923 \mathrm{e}-05$ & \multirow{4}{*}{-3.907582} \\
\hline & $\omega$ & $4.281 \mathrm{e}-04$ & \\
\hline & $\alpha_{1}$ & 0.3462 & \\
\hline & $\beta_{1}$ & 0.3668 & \\
\hline \multirow{5}{*}{$\operatorname{GARCH}(2,1)$} & $\mu$ & $3.272 \mathrm{e}-05$ & \multirow{5}{*}{-3.910558} \\
\hline & $\omega$ & $7.200 \mathrm{e}-04$ & \\
\hline & $\alpha_{1}$ & 0.2375 & \\
\hline & $\alpha_{2}$ & 0.2412 & \\
\hline & $\beta_{1}$ & $1.000 \mathrm{e}-08$ & \\
\hline \multirow{2}{*}{$\operatorname{GARCH}(3,1)$} & $\mu$ & $3.264 \mathrm{e}-05$ & \multirow{2}{*}{-3.903398} \\
\hline & $\omega$ & $7.250 \mathrm{e}-04$ & \\
\hline
\end{tabular}




\begin{tabular}{|c|c|c|c|}
\hline & $\alpha_{1}$ & 0.2315 & \\
\hline & $\alpha_{2}$ & 0.2385 & \\
\hline & $\alpha_{3}$ & $1.000 \mathrm{e}-08$ & \\
\hline & $\beta_{1}$ & $1.000 \mathrm{e}-08$ & \\
\hline \multirow{7}{*}{ GARCH $(4,1)$} & $\mu$ & $3.258 \mathrm{e}-05$ & \multirow{7}{*}{-3.898018} \\
\hline & $\omega$ & $6.887 \mathrm{e}-04$ & \\
\hline & $\alpha_{1}$ & 0.2087 & \\
\hline & $\alpha_{2}$ & 0.2479 & \\
\hline & $\alpha_{3}$ & $1.000 \mathrm{e}-08$ & \\
\hline & $\alpha_{4}$ & $4.590 \mathrm{e}-02$ & \\
\hline & $\beta_{1}$ & $1.000 \mathrm{e}-08$ & \\
\hline \multirow{8}{*}{$\operatorname{GARCH}(5,1)$} & $\mu$ & $3.204 \mathrm{e}-05$ & \multirow{8}{*}{-3.891064} \\
\hline & $\omega$ & $6.895 e-04$ & \\
\hline & $\alpha_{1}$ & 0.2092 & \\
\hline & $\alpha_{2}$ & 0.2369 & \\
\hline & $\alpha_{3}$ & $1.000 \mathrm{e}-08$ & \\
\hline & $\alpha_{4}$ & $3.556 \mathrm{e}-02$ & \\
\hline & $\alpha_{5}$ & $1.317 \mathrm{e}-02$ & \\
\hline & $\beta_{1}$ & $1.000 \mathrm{e}-08$ & \\
\hline \multirow{9}{*}{ GARCH $(6,1)$} & $\mu$ & $2.618 \mathrm{e}-05$ & \multirow{9}{*}{-3.885134} \\
\hline & $\omega$ & $7.134 \mathrm{e}-04$ & \\
\hline & $\alpha_{1}$ & 0.2032 & \\
\hline & $\alpha_{2}$ & 0.2076 & \\
\hline & $\alpha_{3}$ & $1.000 \mathrm{e}-08$ & \\
\hline & $\alpha_{4}$ & $1.000 \mathrm{e}-08$ & \\
\hline & $\alpha_{5}$ & $9.453 \mathrm{e}-03$ & \\
\hline & $\alpha_{6}$ & $3.431 \mathrm{e}-02$ & \\
\hline & $\beta_{1}$ & $1.000 \mathrm{e}-08$ & \\
\hline
\end{tabular}

The best GARCH (p,q) model in Table 8 is the GARCH (2.1) model with the smallest Akaike's Information Criterion (AIC) value of -3.910558.

Based on the skewness value, the ARIMA $(6,1,1)$ and GARCH $(2,1)$ models are asymmetric, because the skewness value is not equal to zero as in Table 2, the distribution can be said to be asymmetric. To overcome the asymmetric nature, it can be continued by estimating the APARCH model (p, q). So that the APARCH $(1,1)$, APARCH $(2,1)$, APARCH $(3,1)$, APARCH $(4,1)$, APARCH $(5,1)$ and APARCH $(6,1)$ models are used. Based on the analysis and parameter estimation obtained the best model, namely APARCH $(1,1)$ model with the smallest Akaike's Information Criterion (AIC) value of -3.8260 as shown in Table 9.

Table 9. APARCH (1.1) Model Selected

\begin{tabular}{rccc}
\hline Model & Parameter & Estimation & AIC \\
\hline & $\mu$ & -0.000270 & \\
\cline { 2 - 3 } APARCH(1,1) & $\emptyset_{1}$ & 0.020648 & \\
\cline { 2 - 3 } & $\emptyset_{2}$ & -0.091118 & \\
\cline { 2 - 3 } & $\emptyset_{3}$ & -0.028152 & \\
\cline { 2 - 3 } & $\emptyset_{4}$ & -0.079523 & \\
\hline
\end{tabular}




\begin{tabular}{cc}
$\emptyset_{5}$ & -0.044700 \\
\hline$\emptyset_{6}$ & -0.098869 \\
\hline$\theta_{1}$ & -0.864089 \\
\hline$\omega$ & 0.014222 \\
\hline$\alpha_{1}$ & 0.478318 \\
\hline$\beta_{1}$ & 0.282267 \\
\hline$\gamma_{1}$ & -0.105698
\end{tabular}

The ARIMA $(6,1,1)$ and APARCH $(1,1)$ model equations used to estimate the VaR value are as follows.

ARIMA $(6,1,1)$ Model:

$$
\begin{gathered}
Z_{t}=-0.000270+0.020648 Z_{t-1}-0.091118 Z_{t-2}-0.028152 Z_{t-3}-0.079523 Z_{t-4}- \\
0.044700 Z_{t-5}-0.098869 Z_{t-6}-0.864089-\varepsilon_{t} .
\end{gathered}
$$

APARCH (1,1) Model:

$$
\sigma_{t}^{2}=0.014222+0.478318\left(\left|\varepsilon_{t-1}\right|+0.105698 \varepsilon_{t-1}\right)^{\delta}+0.282267 \sigma_{t-1}{ }^{2} .
$$

\section{Calculate the VaR value}

The first step taken to determine the value at risk value from the APARCH $(1,1)$ model is to calculate the volatility value at the $95 \%$ confidence level with $\alpha=5 \%$. Based on the Jarque-Bera test, it is found that the bitcoin return data is not normally distributed, so that the $Z_{(1-\alpha)}$ or $Z_{-s c o r e}$ values cannot be used directly. To obtain the $Z_{- \text {score }}$ value, which can be calculated by the Cornish Fisher Expansion with notation $Z_{(1-\alpha)}^{\prime}$, so that

$$
Z_{(1-\alpha)}^{\prime}=Z_{(1-\alpha)}+\frac{1}{6}\left(\left(Z_{(1-\alpha)}\right)^{2}-1\right) \xi
$$

Where, $Z^{\prime}{ }_{(1-\alpha)}=$ new $Z_{- \text {score }}$ with a certain level of confidence, and $\xi=$ skewness coefficient.

Table 10. $\alpha$ Value at $95 \%$ Confidence Level

\begin{tabular}{ccc}
\hline Confidence Level & $\boldsymbol{Z}_{(\mathbf{1}-\boldsymbol{\alpha})}$ & $\boldsymbol{Z}^{\prime}{ }_{(\mathbf{1}-\boldsymbol{\alpha})}$ \\
\cline { 2 - 3 } $95 \%$ & 1.69 & 1.865 \\
\hline
\end{tabular}

Based on Table 10 it is obtained $Z^{\prime}{ }_{(1-\alpha)}$ value of 1.865 with confidence level $95 \%$ or significance level $\alpha=5 \%$. Therefore, the volatility value APARCH $(1,1)$ is obtained by rooting the variance value,

$$
\begin{aligned}
& \sigma_{t}^{2}=0.014222+0.478318\left(\left|\varepsilon_{t-1}\right|+0.105698 \varepsilon_{t-1}\right)^{\delta}+0.282267 \sigma_{t-1}{ }^{2} \\
& \sigma_{t}{ }^{2}=0.0204101266774137 \\
& \sigma_{t}=0.142864
\end{aligned}
$$

By using this volatility value to calculate the VaR value of bitcoin returns,

$$
\begin{aligned}
& V a R=\mu+\sigma_{t} \Phi^{-1}(\alpha) \\
& \operatorname{VaR}=0.26617136
\end{aligned}
$$

Based on this model, the VaR value is calculated at the $95 \%$ significance level with the assumption that the initial investment is IDR $100,000,000$, and the maximum loss to be obtained in the next day is $26,617 \%$ or equivalent to IDR $26,617,000$.

The best model obtained in this study that can be used to calculate the amount of investment risk is APARCH (1.1) model. This model can be used to calculate the risk of 
investing in bitcoin in the future. This is supported by research (Hidayatullah and Qudratullah, 2017) which found APARCH $(1,1)$ model which is used to analyze the risk of investing in Islamic stocks in the next 10 days. And also supported by research (Stavroyiannis, 2016) which shows that APARCH $(1,1)$ model with the standardized Pearson distribution is quite accurate in modeling financial risk, able to analyze finances using the skewed distribution in investment risk management tools. The results of this study can be used as additional information and knowledge about the risk of investing in Bitcoin by applying the VaR-APARCH model.

\section{CONCLUSION AND SUGGESTIONS}

Based on the results of the study, it can be concluded that the best model selection can be seen from the smallest Akaike's Information Criterion (AIC) value, namely ARIMA $(6,1,1)$ model and APARCH $(1,1)$ model with the equation $\sigma_{t}^{2}=0.014222+0.478318\left(\left|\varepsilon_{t-1}\right|+\right.$ $\left.0.105698 \varepsilon_{t-1}\right)^{\delta}+0.282267 \sigma_{t-1}{ }^{2}$. And then, the risk obtained from estimating the VaR value using the APARCH model on the daily closing price data for bitcoin for the period 1 January 2019 untill 31 December 2019 with a 95\% confidence level is $26.617 \%$. If an investor will invest with an initial fund of IDR 100,000,000 then the maximum loss that the investor will get in the next day is IDR $26,617,000$. There are suggestions that need to be developed in further research, namely the need to compare the data model with the previous year, both with data in 2018 and with data in previous years.

\section{REFERENCES}

Ali, G. (2013). EGARCH, GJR-GARCH, TGARCH, AVGARCH, NGARCH, IGARCH and APARCH Models for Pathogens at Marine Recreational Sites. Journal of Statistical and Econometric Methods, 2(3), 5773.

Bakar, N. A., \& Rosbi, S. (2017). Autoregressive Integrated Moving Average (ARIMA) Model For Forecasting Cryptocurrency Exchange Rate In High Volatility Environment: A New Insight of Bitcoin Transaction. International Journal of Advanced Engineering Research and Science, 4(11), 237311.

Chu, D. (2018). Broker-Dealers for Virtual Currency: Regulating Cryptocurrency Wallets and Exchanges. Columbia Law Review, 118(8), 2323-2360.

Conrad, C., Karanasos, M., \& Zeng, N. (2011). Multivariate Fractionally Integrated APARCH modeling of Stock Market Volatility: A Multi-Country Study. Journal of Empirical Finance, 18(1), 147-159.

Didiharyono, D., \& Syukri, M. (2020). Forecasting With ARIMA Model in Anticipating Open Unemployment Rates in South Sulawesi. International Journal of Scientific and Technology Research, 9(3), 3838-3841.

Elvitra, C. W., Warsito, B., \& Hoyyi, A. (2013). Metode Peramalan dengan Menggunakan Model Volatilitas Asymmetric Power ARCH (APARCH). Jurnal Gaussian, 2(4), 289-300.

Epaphra, M. (2016). Modeling exchange rate volatility: Application of the GARCH and EGARCH models. Journal of Mathematical Finance, 7(1), 121-143.

Giot, P., \& Laurent, S. (2013). Market Risk In Commodity Markets: a VaR approach. Energy Economics, 25(5), 435-457.

Guesmi, K., Saadi, S., Abid, I., \& Ftiti, Z. (2019). Portfolio Diversification with Virtual Currency: Evidence from Bitcoin. International Review of Financial Analysis, 63(1), 431-437.

Gunay, S., \& Khaki, A. R. (2018). Best Fitting Fat Tail Distribution for the Volatilities of Energy Futures: Gev, Gat and Stable Distributions in GARCH and APARCH Models. Journal of Risk and Financial Management, 11(2), 30-45.

Hidayatullah, S., \& Qudratullah, M. F. (2017). Analisis Risiko Investasi Saham Syariah Dengan Model Value AT Risk-Asymmetric Power Autoregressive Conditional Heterocedasticity (VaR-APARCH). Jurnal Fourier, 6(1), 37-43. 
Ilupeju, Y. E. (2016). Modelling South Africa's Market Risk Using the APARCH Model and Heavy-Tailed Distributions. Doctoral Dissertation University of KwaZulu-Natal Durban.

Irene, Y., Wijaya, M. Y., \& Muhayani, A. (2020). World Gold Price Forecast using APARCH, EGARCH and TGARCH Model. InPrime: Indonesian Journal of Pure and Applied Mathematics, 2(2), 8-17.

Katsiampa, P. (2017). Volatility Estimation for Bitcoin: A Comparison of GARCH Models. Economics Letters, 158(1), 3-6.

Nugroho, D. B., \& Susanto, B. (2017). Volatility modeling for IDR Exchange Rate Through APARCH Model With Student-t Distribution. In AIP Conference Proceedings 1868 (1) (p. 040005).

Raymaekers, W. (2015). Cryptocurrency Bitcoin: Disruption, challenges and opportunities. Journal of Payments Strategy \& Systems, 9(1), 30-46.

Sovbetov, Y. (2018). Factors Influencing Cryptocurrency Prices: Evidence from Bitcoin, Ethereum, Dash, Litcoin, and Monero. Journal of Economics and Financial Analysis, 2(2), 1-27.

Stavroyiannis, S. (2016). Value-at-Risk and backtesting with the APARCH Model and the Standardized Pearson Type IV Distribution. Available at SSRN 2734058. School of Management and Economics, Technological Educational Institute of Peloponnese.

Syarif, A. (2020). Forecasting the Development of Islamic Bank in Indonesia: Adopting ARIMA Model. JTAM (Jurnal Teori Dan Aplikasi Matematika), 4(2), 190-203.

Thorlie, M. A., Song, L., Amin, M., \& Wang, X. (2015). Modeling and Forecasting of Stock Index Volatility with APARCH Models under Ordered Restriction. Statistica Neerlandica, 69(3), 329-356.

Thorlie, M. A., Song, L., Wang, X., \& Amin, M. (2014). Modelling Exchange Rate Volatility Using Asymmetric GARCH Models (Evidence From Sierra Leone). International Journal of Science and Research, 3(11), 1206-1214.

Tsay, R. S. (2014). Analysis of Financial Time Series. Canada: John Wiley and Sons, Inc. 